\title{
From a Traditional to a Digital Site: 2008-2019. The History of Milan Cathedral Surveys
}

\author{
Cristiana Achille, Francesco Fassi, Alessandro Mandelli, Luca Perfetti, \\ Fabrizio Rechichi and Simone Teruggi
}

\begin{abstract}
Since 2008, an intense survey has been underway in the Milan Cathedral. The operations, over the years, have been conducted with laser scanner and photogrammetry choosing or integrating the different methodologies according to the environment, the necessary "drawing" to support the different sites' maintenance operation but always concurrently with the evolution of the method and the software. The "principal actor" of conservation activities is the "marble block." The Veneranda Fabbrica organizes the activities identifying the areas that are in need of intervention and identifying which blocks will be affected by replacement operations, tessellation, or consolidation. Thus, the objective of the survey activities and the subsequent modeling phase was to build a detailed 3D model in which the marble blocks are easily recognizable in terms of their shape, size, position, and texture (only for the outer part). All the elaborations produced, the 3D models, the two-dimensional representations, and the orthophotos, allow for the identification of the blocks, as to provide proper technical support for site operations. In parallel with the survey and modeling activities, an ad hoc online information system was created to support the construction site activities in a smart manner. The system allows for the consultation and the sharing of the 3D models and all the data necessary for maintenance operations of the entire Cathedral.
\end{abstract}

Keywords Survey $\cdot$ Photogrammetry $\cdot$ Reality-based model $\cdot$ Online information system $\cdot$ VR/AR applications

C. Achille $(\varangle) \cdot$ F. Fassi - A. Mandelli $\cdot$ L. Perfetti $\cdot$ F. Rechichi $\cdot$ S. Teruggi

Architecture, Built Environment and Construction Engineering-ABC Department, Politecnico di Milano, Milan, Italy

e-mail: cristiana.achille@polimi.it

B. Daniotti et al. (eds.), Digital Transformation of the Design, Construction and Management Processes of the Built Environment, Research for Development, https://doi.org/10.1007/978-3-030-33570-0_30 


\section{The Milan Cathedral and the Veneranda Fabbrica: A Brief Historical Introduction}

The construction of the Duomo began in 1386. The promoter of the construction was the archbishop Antonio da Saluzzo and the first patron Gian Galeazzo Visconti (Moschini 2012). Simultaneously with the start of the construction of the Cathedral, Gian Galeazzo Visconti established the Veneranda Fabbrica del Duomo in Milan, a historical institution in charge of preserving and restoring the Cathedral. This institution has been a key player for over 630 years in all the activities of the Cathedral: from maintenance to custody and liturgical service and the valorization and crowdfunding activities to provide for the necessary resources for its continuous maintenance through the century (https://www.duomomilano.it).

The dimensions of the Gothic Cathedral are impressive: it is the third highest, after the Cathedral of Beauvais in France and St. Peter's in Rome, and one of the largest in the world, second only to St. Peter's in the Vatican.

The entire Gothic Cathedral is covered in marble while all decorations, medium/little spires, statues, and its tallest structures are made by marble entirely. The marble itself comes from the quarries of Candoglia and Ornavasso in Val D'Ossola, a white-pink marble deposit, located in the high Alpine foothills between Monte Rosa and Spluga. The marble deteriorates in a short time due to the run-off of rains, pollution and temperature changes and over the years the marble becomes very friable. It could lead to potentially dangerous situations for the structure and the people living in the Cathedral. So one of the essential activities of the Veneranda Fabbrica is a periodical inspection to identify the damaged parts. The necessary maintenance tasks consist of repairing cracked or chipped marble blocks up to their complete replacement in more damaged situations. The activities of the site are organized and carried out block by block, identifying the type of necessary intervention (consolidation, cleaning or replacement) on the single marble block (Monti et al. 2013). This means that all technical representations, 2D or 3D, must accurately and precisely describe the shape and position of the individual blocks of marble (Fassi et al. 2018).

\section{2008-2019: The Survey Activities of the Cathedral}

Among the essential "working tools" of the Veneranda Fabbrica site, are the architectural 2D representations as plans, sections, profiles, and 3D models. They are necessary for the correct documentation and planning of the activities. The technical office of the Fabbrica periodically deals with updating the technical drawings, from the representations that describe the whole structure, in part still on paper, to the accurate representation of smaller parts presenting complex maintenance operations. In order to respond to this need, a survey campaign was launched in 2008 focused on the "Guglia Maggiore", in preparation for the later extraordinary restoration of the following years. Initially, the planned activities included the representation of the Main 
Spire traditionally with predetermined plans and sections of the structures. However, the constant relationship with the Fabbrica site had immediately highlighted the limitations linked to a classic approach. In other words, to follow the activities of a long and complicated construction site, a fixed number of general representations were very limiting. The need of continuous different surveys and representations before and during the restorations has increased the need to overturn the classical processes (2D survey and restitution) in favor of a survey aimed at the production of complete 3D models, from which it is possible to extract any two-dimensional representation when needed. A classic survey and 2D restitution approach always finds a solution, also starting from a complex shape; on the contrary, to create a three-dimensional reality-based model means to solve theoretical and practical problems that are both theoretically and practically challenging. Since the beginning of the activities in 2008, the main issues faced with a technical research approach are as follows:

- the extremely complex object shape, considerably rich in decorations, in narrow passages, and height of out-of-reach structures;

- the management of an impressive amount of data;

- the reality-based modeling phase in terms of time necessary for the realization of accurate and precise 3D models but also in terms of data organization and modeled representation accuracy and details;

- the management of big 3D models both during the modeling phase and also later for the data fruition.

The first part of the activity was aimed at solving the problems that arise in situ: the presence of an active site, scaffolding, narrow spaces, people, inaccessible areas, covered and non-covered spaces, different lighting conditions, times for execution of the surveys dictated by the site (Achille et al. 2012).

It is good to remember that the start of these activities dates back to 2008, so the hardware and software limitations were not trivial. Today, the geometric description makes use of tools that allow users to measure objects of any shape (linear or free form), producing in real time or near real time a three-dimensional portion of data (point clouds). At the beginning of the project the survey technique that allowed us to solve the multiple issues (shape-position-material) was photogrammetry: starting from the traditional digital photogrammetric approach (manual bundle adjustment and stereo plotting) in 2008, up to the experimentation of the emerging semi-automatic image-based techniques in the following years. The photogrammetric survey, although possible, was initially limited by the size of the object itself, which forced users to use an impressive number of images elaborated through manual procedures both in the orientation phase and in the modeling phase for the visual recognition of homologous points. This was the most significant limitation of the 
process since it was extremely time consuming. ${ }^{1}$ Today, the tested automatic imagebased techniques allow for the orientation of a considerable number of images automatically, for the auto calibration of the sensors and for the extraction of dense Digital Surface Models (DSMs) in the form of point clouds comparable (if not superior) to those obtainable with scanner instrumentation (both in terms of maximum resolution achievable and expected accuracy). ${ }^{2}$

The photogrammetric methods are in this way very flexible, allowing users to survey both large architecture and minute decorations, using the same instruments. Another reason why the methods are necessary on the cathedral is because it can adapt itself quickly to the many different situations and "architectural environments". Nevertheless, not always can the methods be used effectively due to architectural or environmental constraints. It is the case of vast interior spaces that are poorly lit by large windows and that are always occupied by liturgical activity and the presence of tourists or, on the contrary, very narrow secondary passages where any survey method couldn't give satisfying results. In order to solve these issues, many tests were conducted both with unconventional range-based (Zeb1, DOT DPI 8, Heron backpack) and image-based methods (fisheye photogrammetry, camera rigs, and panoramic cameras) to identify the optimal strategy for (i) detecting Candoglia marble, (ii) speeding up the survey phase, and (iii) detecting narrow and poorly illuminated spaces. The tests were conducted both inside and outside the Cathedral (Perfetti et al. 2017). The final 3D point cloud format model of the Cathedral derives from the contribution of different survey systems.

Candoglia marble is a material that is difficult to detect with instruments that use laser light. The crystalline structure of the marble allows the laser light to penetrate the surface, giving an incorrect shape (Fassi et al. 2011). After different tests, we identified the Leica C10 scanner as the only instrument capable of scanning marble without penetration. It was used inside the Cathedral to survey all the naves, substituting the photogrammetric technique because time consuming. The designed scans were acquired both from the ground and two upper levels (totally 850 scans), using a lifting platform, in order to avoid shadow areas and guarantee a uniform resolution

\footnotetext{
${ }^{1}$ At the beginning of 2008 , the laborious photogrammetric pipeline (image acquisition, manual orientation, and restitution) produced a wireframe model. For each stereoscopic pair, the operator had to identify common points (orientation) and then-on the stereoscopic model—proceed with returning the shape profile manually. Several days of work were required to get all 3D lines and to construct the three-dimensional wireframe representation. To create the final surface model, yet another processing step via an external piece of software was needed.

${ }^{2}$ These features and automations are the evolution of the classic and consolidated photogrammetric rules combined with the developments proposed by the world of Computer Vision. An example is the Amadeo spire, dimensions: base $3.10 \mathrm{~m} \times 3.10 \mathrm{~m}$, height $20.5 \mathrm{~m}$. Time required for the survey: 1 week; for processing data: 5 weeks. Elaborated products: dense point cloud, orthophotos (eight exterior sides and eight inner sides). Total images acquired: 8160 (6180 from the scaffolding, 163 from the level of the roofs, 23 from the elevator, and 1793 from the interior of the staircase). Digital cameras used: Nikon D810, 36MP, f: $12 \mathrm{~mm}, \mathrm{GSD}=0.8 \mathrm{~mm}$; f: $50 \mathrm{~mm}, \mathrm{GSD}=1.5 \mathrm{~mm}$; f: $8 \mathrm{~mm}$ fisheye. Canon 5DmkIII, 24MP, f: $85 \mathrm{~mm}, \mathrm{GSD}=2.2 \mathrm{~mm}$. 1:10 for external facade, $1: 20$ for interior facade.
} 
of $5 \mathrm{~mm}$ and consequently a fixed accuracy suitable for a 1:50 and 1:20 representation scale. Currently - in 2019 - the survey of the whole interior Cathedral is almost complete, so it is possible to explore the 3D model of the Duomo in a point cloud format. Due to the size of the Cathedral, traditional topographic measurements have always been necessary to accurately align the point clouds within a single reference system and to check all the photogrammetric elaborations. The cleaning phase of the scans was completely manual. The final size of the point cloud does not allow for management through a single file; the data was segmented following the logic of the site areas of the Veneranda Fabbrica (inferior nave, middle nave, central nave, apse, and choir). This allows to efficiently use the data during the restitution phase. The survey of the external facades, of the roofs and the falconature, ${ }^{3}$ has been realized only through photogrammetry. It is easy to understand as it was not possible to use the scanner to survey the highest parts due to the impossibility of positioning the equipment in a stable position. Instead, it was possible to use the elevating platform for a photogrammetric survey. In this way, roofs and the highest spires and decorations of the facades were also surveyed. ${ }^{4}$ The main goal was to produce high-resolution orthophotos of the facades with a restitution scale equal to 1:50; while the sectors of the roof, delimited by arches and falconature, were elaborated at a 1:20 scale.

All point clouds produced bit by bit are generating the complete $3 \mathrm{D}$ dense point cloud model of the Duomo (Fig. 1). This raw model can be used for visualization, measurement operations, features extraction or as a base for orthophoto generation.

In order to obtain a 3D surface model, a time consuming and arduous reality-based modeling and simplification phase is required. It is necessary to produce BIM-like models that can be easily modified or used for classical CAD applications (Achille et al. 2014).

For the first research activity of the Main Spire, a complete and detailed 3D model was created with the double aim of

(i) automatically extracting all the metric information useful for the restoration of the Cathedral with a useful accuracy for a 1:20 and/or 1:50 scale,

(ii) being the basis of an information system supporting site activities. For this reason, the 3D reality-based models describe all the individual objects, each block of marble, every decorative element, or statue.

The modeling phase was not easy, so different methods and software were tested to find a satisfactory method in terms of achievable accuracy and time needed for its realization. ${ }^{5}$ In addition to the nurbs models elaborated with SW Rhinoceros (the

\footnotetext{
${ }^{3}$ Crowning elements of the Duomo (Benati et al. 2001).

${ }^{4}$ An example. South façade, digital orthophoto 1:50 scale, obtained by mosaicking 33 ortho images. 7.586 images (4.511 from elevator; 205 from ground level; 1.936 from roof level; 934 for apse). Five different full-frame camera configurations (Canon 5DSR, 51MP, f: $35 \mathrm{~mm}$, Ground Sample Distance $=1,8 \mathrm{~mm}$; f: $85 \mathrm{~mm}$, GSD $=2,4 \mathrm{~mm}$; Canon 5DmkIII, 24MP, f: $85 \mathrm{~mm}$, GSD $=$ 1,6 mm; Nikon D810, 36MP, f: $50 \mathrm{~mm}, \mathrm{GSD}=1,5 \mathrm{~mm}$; f: $24 \mathrm{~mm}, \mathrm{GSD}=2,0 \mathrm{~mm}$.

${ }^{5}$ In addition to direct modeling, a number of tests of parametric modeling were made. This approach is possible only when the element is repeated with the same shapes, but with different sizes and can be used only where the simplification respects the precision requirements. Some tests were done
} 


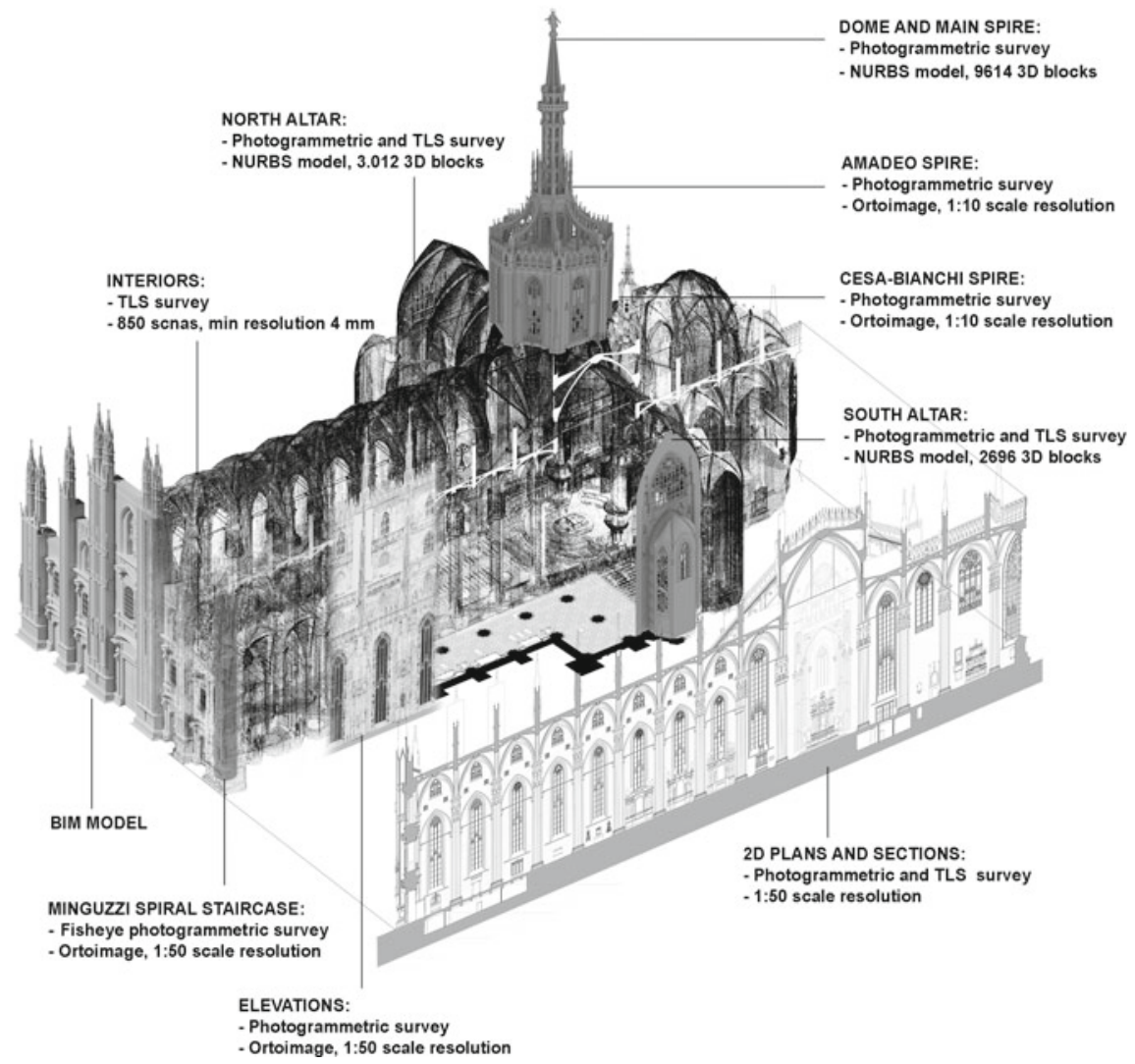

Fig. 1 The image aims to represent the types of survey and elaborations carried out in these years for the Duomo research projects. The scanner and photogrammetric survey produced a huge point cloud of the Duomo; data processing is progressively generating classical two-dimensional representations (plans, profile sections) and 3D models (mesh, nurbs, BIM)

Main Spire, the Dome Cladding and the vault, the internal facades of the transept, with the altars and portions of the roof), other modeling tests are underway using BIM software (Revit and Archicad). Some areas were chosen, consisting both of simple and free-form objects (the façade, a portion of roofs, the pillars and the vaults of the lower nave) in order to assess accuracy versus time, the level of interoperability from and to other software (Tommasi et al 2016; Achille and Tommasi 2017), the possibility of linking information (vector, raster and textual) and the possibility of managing site activities using the specific tools that this software provides.

The use of all the different elaborated 3D models, even only in terms of visualization, requires specific skills and enormous computational resources. In order to

for the series of gothic windows and for the pyramid on top of the main spire. In the case of the windows of the transept altars, the parametric approach (Rhino + Grasshopper) led to a significant reduction in the time, from an expected $330 \mathrm{~h}$ for direct modeling to 126 with parametric modeling. 
facilitate the use of 3D models for everyday users as well, to allow the parallel modification of the $3 \mathrm{D}$ inside the modeling software and to provide a further potential to the model itself, a dedicated BIM-like system was implemented.

\section{The Web-Based Informative System}

The research had to immediately deal with the problems relating to the management and use of the three-dimensional models produced. The main issues identified were:

(i) a smart management system: The complete 3D model is vast in terms of "quantity of modelled objects" and resources needed for loading and visualization. Even today (2019) they cannot be managed simultaneously in any software;

(ii) an easy fruition: Because such a complex model requires simple and intuitive consultation methods to be also used by the general public;

(iii) continuous updating: It is necessary to guarantee a constant updating of the model itself, in support of future maintenance activities.

The information system (Fassi and Parri 2012; Fassi et al. 2015) specifically developed for the Veneranda Fabbrica ${ }^{6}$ is composed of three parts. The first part refers to the modeling environment ${ }^{7}$ where the model is created, modified, updated, and it is also possible to link it to the information database. The 3D models, once completed, are exported and are prepared to be used through the web interface, the second part of the system. It is sufficient to have access to a web browser (via PC, notebook, tablet, or smartphone) to view models at different levels of detail. ${ }^{8}$ Models built with any modeling software can be displayed and can have a simple shape (structure) or complex forms (free-form models) or both possibilities integrated with one another. The system has no restrictions on the number of objects that can be viewed at the same time, as well as on the level of detail of the same. ${ }^{9}$ The third part of the online information system consists of a database that contains both 3D models and associated information. The database ${ }^{10}$ (PostgreSQL) allows operators

\footnotetext{
${ }^{6}$ The system created for the Milan Cathedral is to be considered as a system made specifically to support the Veneranda Fabbrica activities. A general system that adapts to the world of Cultural Heritage is under development with the name BIM3DSG (patent pending MI2014A002016).

${ }^{7}$ The choice of modeling software had a relapse (2009) in the Rhinoceros software to guarantee reality-based modeling (from a point cloud). The software allows for the creation of scripts in $\mathrm{C}$ language and therefore to build ad hoc tools according to specific needs. The plug-ins developed were written in C\# and .NET while a windows form was used for the user interface (in the latest version of the system the plug-ins use WPF Windows Presentation Foundation, Xceed WPF Toolkit, a version of Avalon-Dock and ITinnovationsLibrary).

${ }^{8}$ It is possible to use devices even with limited hardware resources because the system allows objects to be displayed at different levels of detail, automatically calculated by the system.

${ }^{9}$ Powerful caching mechanisms have been implemented to ensure ease and speed of use of the system; the download is almost instantaneous, even if the available connection is slow.

${ }^{10}$ The DB is installed on a remote server and is accessible from a variety of devices via Internet connection. Only if necessary, the DB can be installed locally and managed within a local network.
} 
to share and synchronize changes in real time; it contains all the information relating to the internal structure, textual information, and model files entered by users. The system can be used both by a specialized user (who also accesses the first part of the system) and a non-specialized one. It allows users (i) to view all or part of the models; (ii) to automatically calculate metric information of each object such as area, volume, and position; (iii) to display/add/modify information and files (raster, text, and vector) associated with one or more objects. The system also allows users to create (both inside the modeling software and the web interface) records of maintenance activities (cleaning, tessellation, or replacement), whether they be planned, ongoing or already completed. A series of functions have been designed to add/modify/see ongoing maintenance activities with all the related information (photos, texts, videos, documents, dwg, etc.) using visualization with different colors directly on the web viewer (Achille and Fassi 2016).

The designed system not only allows for records of information on interventions but also helps the real-time updating of 3D parts. In this way, the visualized 3D model always represents the latest state of the art of the object after the last intervention (Fig. 2). Using the system with portable devices (tablets, smartphones, etc.) the operator can update the information directly on site. The information, once entered, is saved in the system database and visible to any other user (Fig. 3). The management of 3D models through the WEB system guarantees: (i) the low-cost essence of the system (free browser); (ii) simultaneous access by multiple users (usability); iii) interoperability between different actors (participation); (iv) the immediate updating and synchronization of data entered.

\section{Future Research}

The three-dimensional survey started in 2008 and which is now almost complete, aims at achieving the geometrical knowledge of the Duomo, a starting point for conservation, diagnosis, monitoring, and therefore for safeguarding the Cathedral. For this reason, all survey activities are conducted with a metrological point of view guaranteeing the uniformity of the resolution, the completeness of data, and a mean accuracy under the centimeter. The metric representations (2D or 3D) required for the Duomo (high-resolution orthophotos and reality-based models) need a design phase, long elaboration processes and check phases. The new data acquisition and processing tools lead to a significant reduction in the time required, but, particularly, they make it possible to achieve the once unthinkable both in terms of general feasibility and available resolution and precision . 


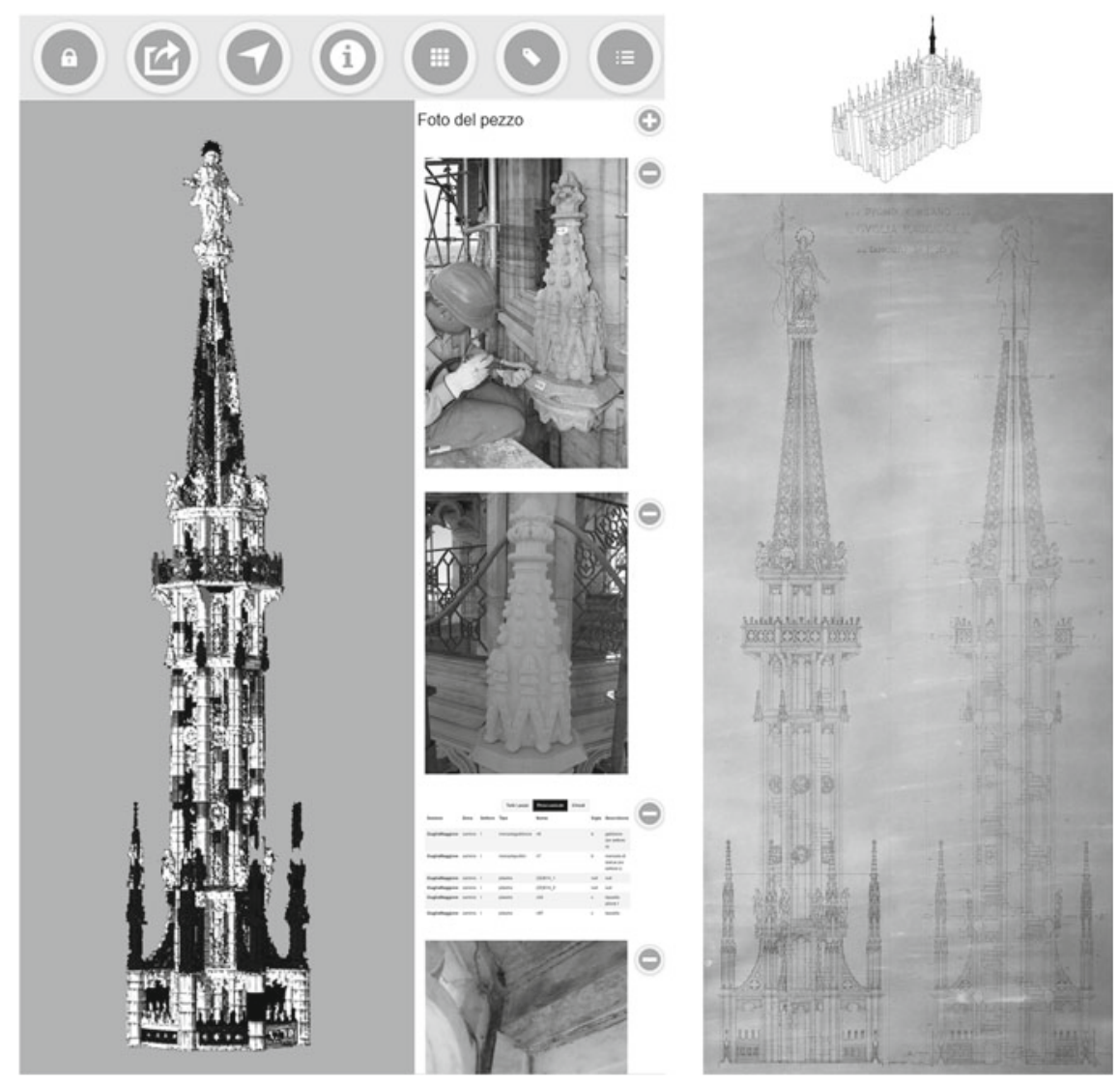

Fig. 2 On the left, a detail of the final part of the Main Spire visualized on the online system. The blocks subject to intervention (different colors according to the type of intervention) with some example images are provided; on the right the same detail in the original drawing made by Veneranda Fabbrica, on 1:20 scale, January 7, 1941

The bottleneck of the whole process is the modeling phase. For this reason, the Nurbs modeling activity was interrupted after the "Main Spire research project". The future research topic is to skip this stage and create a 3D system able to use the point cloud directly as a 3D reference model. Nowadays, the survey techniques produce, in one way or another, a point cloud, which already constitutes an archive of the geometry of the object that can be used conceptually in professional processes. For these prospects, the contribution of tools designed and developed ad hoc is decisive. 

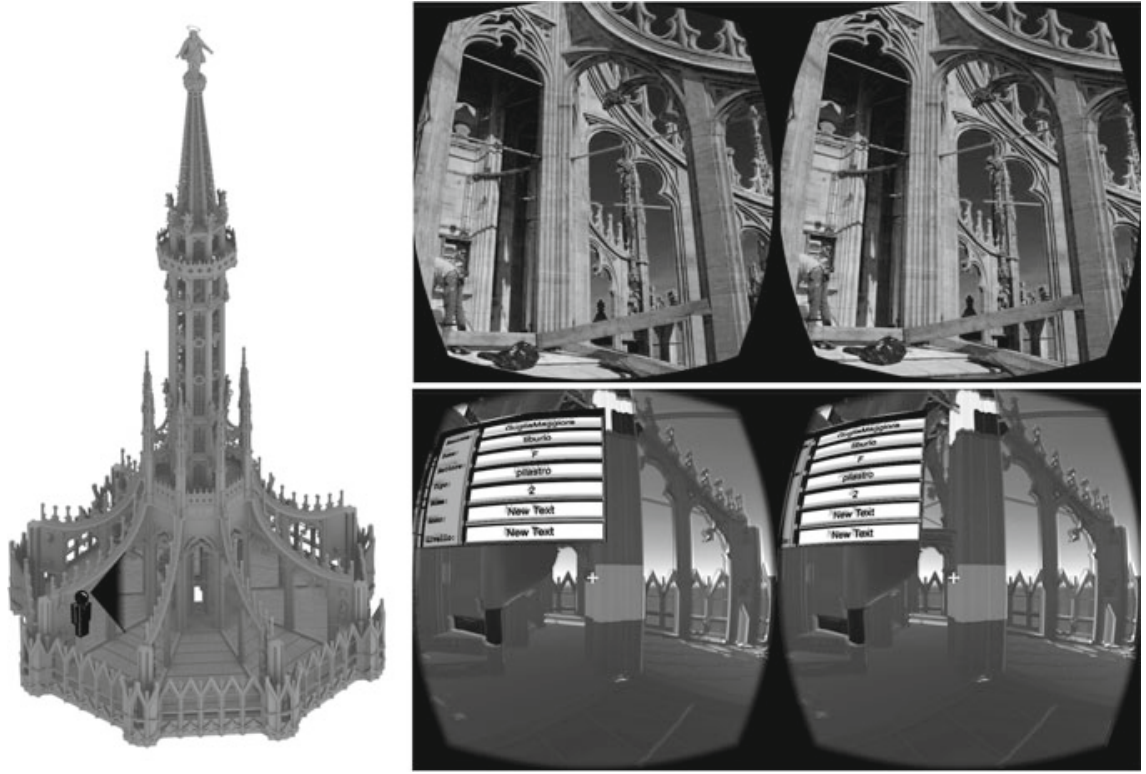

Fig. 3 Main Spire BIM system, stereoscopic rendering through Oculus Rift DK2

Acknowledgements The authors would like to thank Francesco Canali, the "Architect" of the Duomo, and the whole staff, in particular, Francesco Aquilano and the Massimiliano Regis. Furthermore, the authors would like to thank all the colleagues and students who have contributed to this project to date. Thanks to Benigno Mörlin Visconti Castiglione, the former "Architect" of the Duomo at the time when the research started.

\section{References}

Achille C, Fassi F, Fregonese L (2012) 4 Years History: from 2D to BIM for CH. The main spire on Milan Cathedral. In: Guidi G, Addison AC (eds) Proceeding of VSMM 2012. Virtual Systems in the Information Society, IEEE, pp 377-382. ISBN 9781467325622

Achille C, Fassi F, Mandelli A, Moerlin B (2014) The yards of the Milan Cathedral: tradition and BIM. In: Proceedings of the international conference preventive and planned conservation Monza, Mantua, 5-9 May 2014. ISBN 978-88-404-0318-2

Achille C, Fassi F (2016) Rilievo, modellazione e gestione BIM dei cantieri del Duomo di Milano. In: Eastman C, Teicholz P, Sacks R, Liston K, Di Giuda G, Villa V, Hoepli (eds) 'Il BIM Guida completa al building information'. ISBN 9788820367053

Achille C, Tommasi C (2017) Interoperability matter: levels of data sharing, starting from a 3D information modeling, vol XLII-2/W3. https://doi.org/10.5194/isprs-archives-xlii-2-w3-623-2017

Benati G, Roda AM (a cura di) (2001) Il Duomo di Milano Dizionario storico artistico e religioso Nuova edizione rivista e aggiornata Boniardi. ISBN 8870232700

Fassi F, Parri S (2012) Complex architecture in 3D: from survey to web. Int J Herit Digit Era 1:379-398. ISSN 2047-4970 
Fassi F, Achille C, Mandelli A, Rechichi F, Parri S (2015) A new idea of BIM System for visualization, web and using huge complex 3D model for facility management. Int ISPRS XL-5/W4:359366. https://doi.org/10.5194/isprsarchives-xl-5-w4-359-2015

Fassi F, Achille C, Fregonese L (2011) Surveying and modeling the Main Spire of Milan Cathedral using multiple data sources. Photogram Rec 26:462-487. https://doi.org/10.1111/j.1477-9730. 2011.00658.x

Fassi F, Achille C, Mandelli A, Perfetti L, Polari C (2018) Recording the marble blocks of the Milan Cathedral: synergy between advanced survey techniques. In: Proceedings of the international masonry society conferences 2-s2.0-85062311862

Monti C, Moerlin B, Fassi F, Achille C, Mandelli A (2013) From the digital to the physical model. Case study in the yard of the Milan Cathedral. Mo.Di.Phy Modeling from digital to physical innovation in design languages and project procedures Maggioli Editore. ISBN 9788838762741

Moschini C (2012) a cura di, Il cantiere del Duomo di Milano Dai maestri del lago di Lugano a Leonardo, Silvana Editoriale

Perfetti L, Polari C, Fassi F (2017) Fisheye photogrammetry: tests and methodologies for the survey of narrow spaces. ISPRS XLII-2/W3. 3D Virtual reconstruction and visualization of complex architectures. https://doi.org/10.5194/isprs-archives-xlii-2-w3-573-2017

Tommasi C, Achille C, Fassi F (2016) From point cloud to BIM: a modeling challenge in the Cultural Heritage field. ISPRS XLI-B5. https://doi.org/10.5194/isprsarchives-xli-b5-429-2016

Open Access This chapter is licensed under the terms of the Creative Commons Attribution 4.0 International License (http://creativecommons.org/licenses/by/4.0/), which permits use, sharing, adaptation, distribution and reproduction in any medium or format, as long as you give appropriate credit to the original author(s) and the source, provide a link to the Creative Commons license and indicate if changes were made.

The images or other third party material in this chapter are included in the chapter's Creative Commons license, unless indicated otherwise in a credit line to the material. If material is not included in the chapter's Creative Commons license and your intended use is not permitted by statutory regulation or exceeds the permitted use, you will need to obtain permission directly from the copyright holder.

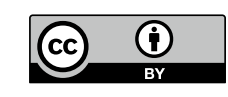

